\title{
Retentive Comparison of Overdenture Attachment Systems On Straight and Divergent Dental Implants
}

Christopher Heath Wine

Follow this and additional works at: https://researchrepository.wvu.edu/etd

\section{Recommended Citation}

Wine, Christopher Heath, "Retentive Comparison of Overdenture Attachment Systems On Straight and Divergent Dental Implants" (2015). Graduate Theses, Dissertations, and Problem Reports. 6961. https://researchrepository.wvu.edu/etd/6961

This Thesis is protected by copyright and/or related rights. It has been brought to you by the The Research Repository @ WVU with permission from the rights-holder(s). You are free to use this Thesis in any way that is permitted by the copyright and related rights legislation that applies to your use. For other uses you must obtain permission from the rights-holder(s) directly, unless additional rights are indicated by a Creative Commons license in the record and/ or on the work itself. This Thesis has been accepted for inclusion in WVU Graduate Theses, Dissertations, and Problem Reports collection by an authorized administrator of The Research Repository @ WVU. For more information, please contact researchrepository@mail.wvu.edu. 


\title{
Retentive Comparison of Overdenture Attachment Systems On Straight and Divergent Dental Implants
}

\author{
Christopher Heath Wine, D.D.S. \\ Thesis submitted \\ to the School of Dentistry \\ at West Virginia University \\ in partial fulfillment of the requirements for the degree of \\ Masters of Science in \\ Prosthodontics
Matthew Bryington, D.D.S, M.S., Chair
Michael Bagby, D.D.S, PhD., M.S.
Brian Dye, D.D.S, M.S
Richard Jurevic, D.D.S., M.S.D, PhD. \\ Morgantown, West Virginia \\ 2015
}

Keyword:

Locator;GPS;Implant;Attachement;Overdenture;Retention;Angled;Zest Anchors; Implant Direct

Copyright 2015 Christopher Wine 


\title{
Abstract \\ Retentive Comparison of Overdenture Attachment Systems On Straight and Divergent Dental Implants
}

\author{
Christopher Heath Wine, D.D.S.
}

Objectives: To investigate the retentive capabilities of the LOCATOR (ZEST Anchors LLC, Escondido, CA USA) attachment and GPS (Implant Direct Sybron International, LLC, California, USA) dental implant attachment systems on parallel and divergent implants after cyclic wear.

Methods: An acrylic rod was cut into blocks representing 20 mandibular arches. Each block had either two LOCATOR or two GPS abutment analogs placed parallel or with 10 degrees of divergence. The associated housings were picked up in corresponding acrylic blocks with Ortho resin (Dentsply GAC, Islandia, NY USA). The black processing liners in each housing were replaced with a $1.5 \mathrm{lb}$ retentive liners. These blocks then had an eyebolt attached so each block could be attached to an Instron 5565 Universal Testing Machine (Instron, Northwood, MA USA). Each block with the retentive housings was repeatedly pulled from the block containing the abutment analogs and retentive force needed for dislodgement was measured at pull $1,50,100,150,200,250,300,350,400,450$ and 500.

Results: The data for each test sample was recorded and an ANOVA was preformed in JMP software (SAS Cary, NC USA). The type of attachments and the amount of pulls showed statistical significance however, the angle of the implants did not. Overall, the LOCATOR had $5.9 \mathrm{~N}$ or $61 \%$ more retention then that GPS attachment.

Conclusion: The GPS attachment had greater initial retention but after 50 cycles of seating and unseating the retention was less than that of a LOCATOR attachment. After 500 cycles of seating and unseating the LOCATOR had 56.72\% more retention on parallel implants and $40.21 \%$ more retention on angled implants. 


\section{Table of Contents}

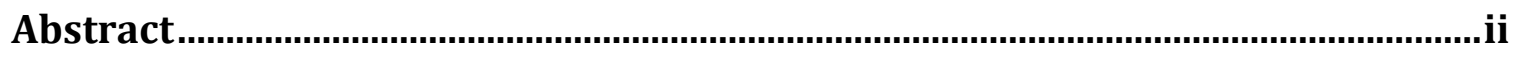

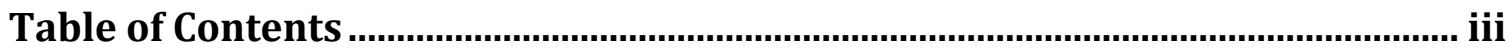

List of Tables ...........................................................................................................

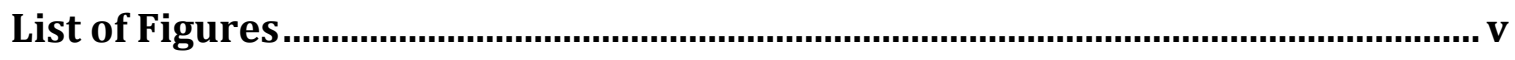

Chapter I - Introduction...................................................................................... 1

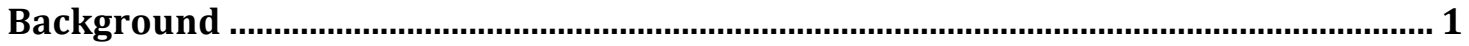

Statement of Problem ............................................................................................ 2

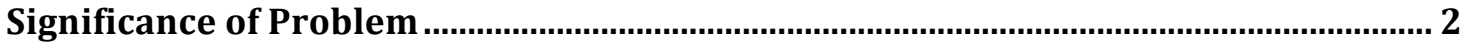

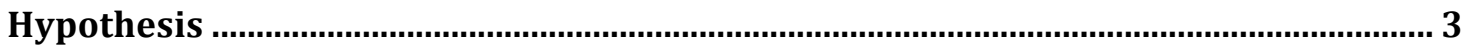

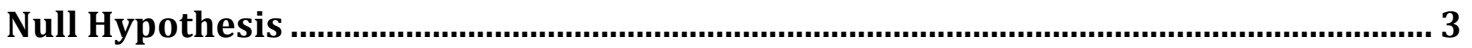

Definition of Terms ................................................................................................................... 3

Assumptions ................................................................................................................... 4

Limitations ................................................................................................................................ 4

Delimitations.................................................................................................................... 4

Chapter II - Literature Review.......................................................................... 5

Mandibular Dentures ........................................................................................................ 5

Mandibular Overdentures ...................................................................................................... 5

Dental Implants.................................................................................................................. 5

Mandibular Implant Overdentures ............................................................................. 6

Dental Implant attachment systems ............................................................................ 6

Studies of Retention ....................................................................................................................... 7



Construction of the Apparatus .................................................................................... 8

Research Design ............................................................................................................. 9

Protocol.................................................................................................................................... 9

Statistical Analysis ................................................................................................ 9

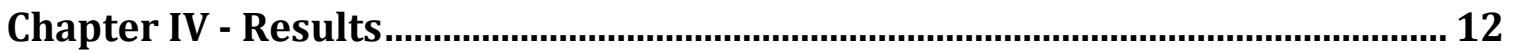

Discussion ......................................................................................................................................17

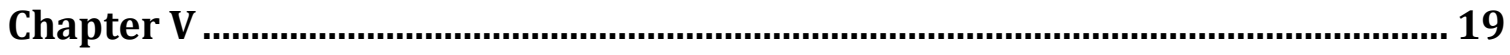

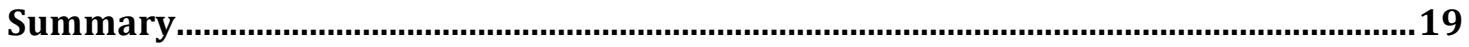

Conclusions .................................................................................................................. 19

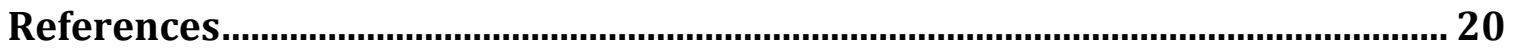

Curriculum Vitae...................................................................................... 25 


\section{List of Tables}

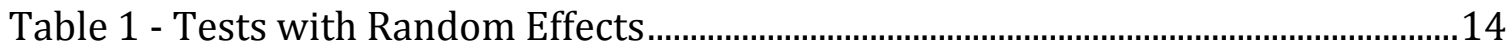

Table 2 - Least Squares Means Table by Attachment .....................................................15

Table 3 - Least Squares Means Table by angle and attachment.......................................15

Table 4 - Initial and Final Retention for the Sample Groups ..............................................17 


\section{List of Figures}

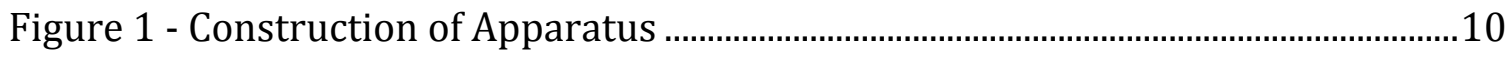

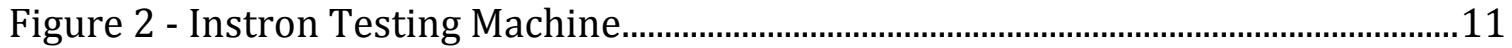



Figure 4 - Means and Standard Deviation plot for parallel GPS attachment.................12

Figure 5 - Means and Standard Deviation plot for parallel LOCATOR attachments...12

Figure 6 - Means and Standard Deviation plot for Locator attachments with 10 degrees of divergence...................................................................................................13

Figure 7 - Means and Standard Deviation plot for GPS attachments with 10 degrees

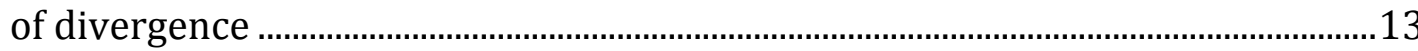

Figure 8 - Means plot for Locator and GPS attachments that are parallel or have 10



Figure 9 - Least Squares means by angle and attachment...............................................15

Figure 10 - Least Square Means Plot for Pull ……..............................................................16

Figure 11 - Least Square Means Plot for Pull and Attachment........................................16

Figure 12 Stephens' and Wine's retentive capacity of LOCATOR attachments............18 


\section{Chapter I}

\section{Introduction}

\section{Background}

Edentulism has been a problem that dentists have had to combat since the beginning of the profession. There have been many advances in the previous decades that have given dentists options for replacing missing teeth with Removable prostheses. The simplest of these modern day prostheses started in the 1850's when Claudius Ash and Seymour White developed porcelain teeth and Nelson Goodyear patented a process for vulcanizing rubber to create a serviceable denture base (Fenton, 1998). Today, the porcelain teeth and vulcanized rubber are usually replaced with resin composite teeth and Polymethyl methacrylate (Pmma) denture bases.

Regardless of the materials and methods used to construct complete dentures, the retention relies on the same basic principles of atmospheric pressure, adhesion, cohesion, mechanical locks, muscle control, and patient tolerance (Rahn \& Heartwell, 1993). In addition, the tongue because of its individual size, form, and activity complicate the impression procedure for the lower denture and also the patient's ability to manage the denture (Zarb, Bolender, Eckert, \& Boucher, 2004). Once the mandibular denture is inserted the tongue continues to have a tendency for movement, which constantly threatens the retention of it (Zarb et al., 2004). In many cases dental implants can help in a mandibular denture by being a supplemental source of retention.

Several studies have demonstrated that there is a significant increase in patient satisfaction with mandibular implant retained overdenture treatment when compared with conventional denture therapy (Burns, 2000; Dias, Moghadam, Kuyinu, \& Jahangiri, 2013). The mandibular 2-implant overdenture has even been considered as the first choice standard of care for edentulous patients (Feine et al., 2002). With the increase in edentulous patients receiving this treatment, the restoring dentist has many options as to what dental implant anchor system to use to retain the implant retained overdenture. 


\section{Statement of Problem}

What are the retentive values of the GPS (Implant Direct Sybron International, LLC, California, USA) and the LOCATOR (ZEST Anchors LLC, Escondido, CA USA) dental implant anchor systems on two implant abutments with up to 10 degrees of divergence?

\section{Significance of Problem}

Studies have associated a mandibular two-implant overdenture with a higher level of patient satisfaction. Thomason showed that there was an approximately $36 \%$ higher satisfaction rate in patients with a conventional maxillary denture opposing a 2 implant mandibular overdenture when compared to wearers of maxillary and mandibular conventional dentures (Thomason, Lund, Chehade, \& Feine, 2004). It has also been shown in a systematic review that while the chewing efficiency gained from a mandibular implant retained overdenture varies from wearer to wearer, those individuals who have difficulty adapting to complete dentures show improvement (Fueki, Kimoto, Ogawa, \& Garrett, 2007).

Due to the complexity of the prosthesis, there is more preplanning that has to be completed for a 2-implant overdenture than a conventional denture. The planning must start with a three dimensional analysis of the restorative space, which takes into consideration the required dimensions for the denture base, appropriately positioned denture teeth, and the planned implant attachment system (Ahuja \& Cagna, 2010). Inadequate space for prosthetic components can result in an over contoured prosthesis, excessive occlusal vertical dimension, fractured teeth adjacent to the attachments, attachments separating from the denture, fracture of the prosthesis, and overall patient dissatisfaction (C. K. Lee \& Agar, 2006).

Once the surgical phase of placing the implants is completed, the restoring dentist must place an implant attachment system to retain the denture. The LOCATOR attachment system (ZEST Anchors LLC, Escondido, CA USA) has quickly gained widespread popularity since its introduction in 2001 due to its simplicity and modest space requirements (Stephens, di Vitale, O'Sullivan, \& McDonald, 2014). In 2013, a system similar to the LOCATOR called the GPS attachment system (Implant Direct Sybron International, LLC, California, USA) was introduced with claims of better performance on implants with 10 degrees of divergence. No study has compared the Locator attachment directly to the GPS attachment. 


\section{Hypothesis}

There will be a significant difference in the retention of the LOCATOR and GPS attachment systems on parallel and divergent implants.

\section{Null Hypothesis}

There will be no significant difference in the retention of the LOCATOR and GPS attachment systems on parallel and divergent implants.

\section{Definition of Terms}

1. Retention - that quality inherent in the dental prosthesis acting to resist the forces of dislodgment along the path of placement (GPT, 2008).

2. Stability - the quality of a removable dental prosthesis to be firm, steady, or constant, to resist displacement by functional horizontal or rotational stress (GPT, 2008).

3. Overdenture - any removable dental prosthesis that covers and rests on one or more remaining natural teeth, the roots of natural teeth, and/or dental implants; a dental prosthesis that covers and is partially supported by natural teeth, natural tooth roots, and/or dental implants (GPT, 2008).

4. Dental Implant - a prosthetic device made of alloplastic material(s) implanted into the oral tissues beneath the mucosal or/and periosteal layer, and on/or within the bone to provide retention and support for a fixed or removable dental prosthesis (GPT, 2008).

5.Dental Implant System - dental implant components that are designed to mate together. An implant system can represent a specific concept, inventor, or patent. It consists of the necessary parts and instruments to complete the implant placement and abutment components (GPT, 2008).

6. Abutment - 1.: that part of a structure that directly receives thrust or pressure; an anchorage 2: a tooth, a portion of a tooth, or that portion of a dental implant that serves to support and/or retain a prosthesis (GPT, 2008).

7. Locator - a resilient stud attachment manufactured by Zest anchors and used for single dental implants with a prefabricated metal matrix abutment and a housing which retains a patrix plastic retention cap that can have varying degrees of 
retention.

8. GPS - a resilient stud attachment manufactured by Implant Direct and used for single dental implants with a fabricated metal matrix abutment and a housing, which retains a patrix plastic retention cap that can have varying degrees of retention.

9. Attachment -1: a mechanical device for the fixation, retention, and stabilization of a prosthesis 2 . A retainer consisting of a metal receptacle and a closely fitting part; the former (the female [matrix] component) is usually contained within the normal or expanded contours of the crown of the abutment tooth (or implant) and the latter (the male [patrix] component), is attached to a pontic or the denture framework (GPT, 2008).

10. Osseointegration - 1: the apparent direct attachment or connection of osseous tissue to an inert, alloplastic material without intervening connective tissue 2 . The process and resultant apparent direct connection of an exogenous materials' surface and the host bone tissues, without intervening fibrous connective tissue present the interface between alloplastic materials and bone (GPT, 2008).

\section{Assumptions}

1. It is assumed that LOCATOR attachments by Zest Anchors International are currently the gold standard of overdenture attachments in dentistry.

2 . The rigid fixation of the abutment analogs in acrylic is assumed to simulate the attachment abutment secured to an osseointegrated implant.

\section{Limitations}

Limitations in this research include variations in the placement of the analogs, processing of the housings into the acrylic blocks, and the possibility of human errors.

\section{Delimitations}

1. The calibration on of the Instron Mechanical Testing Machine

2. The necessity of equalizing the load of the machine for all samples

3. Lack of lubrication within the system which exist in vivo 


\section{Chapter II}

\section{Literature Review}

\section{Mandibular Dentures}

For the new denture wearer, the expectations for a complete mandibular denture have to be set at a realistic level. Swenson quoted in his book "the lower denture is seldom equal to the upper in ability to remain in place or to withstand biting pressure (Swenson, 1959)." The maximum biting force for complete denture is about one third of that of natural teeth and the amount of mucosa to support a complete denture in the edentulous mandible is approximately $12.35 \mathrm{~cm}^{2}$ which is about half of what is available in the edentulous maxilla (Zarb, Bolender, Hickey, \& Carlsson, 1990). In the mandible, there is a large muscle in the form of the tongue that when active can dislodge a mandibular denture. Retention of mandibular dentures depends upon a seal in the same manner as a maxillary denture, but the seal area is not as readily located, and it has considerable movement during ordinary functions of the mouth (Wright, 2004). Complete denture wearing revealed a continued reduction of the residual ridges, but the magnitude of this reduction varied greatly in different individuals (Tallgren, 2003).

\section{Mandibular Overdentures}

The overdenture technique was originally introduced to address the need for maximum support in morphologically compromised dental arches with a desire to improve equally compromised esthetic appearance caused by undersupported circumoral tissues (Zarb et al., 2004). Originally, an overdenture was a complete denture that has one or more tooth roots to provide support. This concept of an overdenture was first described in the mid nineteenth century by Atkinson and Ledger(Ettinger, 2014). Typically the remaining supporting tooth roots have received endodontic therapy. Van Waas showed that retention of even poor quality canine roots beneath a mandibular denture in immediate denture patients reduced the collapse of the alveolar processes in all regions of the mandible (Van Waas et al., 1993).

\section{Dental Implants}

Throughout history, different objects have been historically implanted into the hard and soft tissue of the mouth to replace teeth. In the early $19^{\text {th }}$ century, experiments of implanting objects in the shape of the roots of teeth had started. By 1946 Strock introduced the first two-piece implant and in 1952 Branemark started his experiments that would lead to what he would later call osseo-intergration (Misch, 
2005). Both the two-piece implant and osseo-intergration are principles that a majority of modern day implants are based on. The two-piece implant allows the restorative component of the implant to be separate from the surgical component. This allows the restoring dentist a freedom to use an implant for multiple situations whether it is replacing a single tooth or an edentulous arch.

\section{Mandibular Implant Overdentures}

Studies show that a two-implant mandibular overdenture on two stud attachments provides high patient satisfaction (J. Lee, Kim, Shin, \& Bryant, 2012; Wismeijer, Waas, Vermeeren, Muldel, \& Kalk, 1997). Burns et al (Burns, Unger, Coffey, Waldrop, \& Elswick, 2011) evaluated 3 different mandibular implant overdenture treatments with respect to prosthesis retention and stability, tissue response, patient satisfaction and preference, and complications to determine treatment outcomes. His three treatment groups were two independent ball attachments with 0-rings, a 2-implant bar and a 4-implant bar. His results showed the most favorable responses were typically found with the 0-ring treatment, and the least favorable with the 4-implant bar treatment. Sadowski did a literature review on mandibular implant-retained overdentures. He concluded mandibular implant overdentures appear to show higher patient satisfaction scores than complete dentures and that when 2 implants are used in the anterior mandible to retain an overdenture, solitary ball attachments appear to be less costly, less technique sensitive, and more accommodating of tapered arches (Sadowsky, 2001).

\section{Dental Implant attachment systems}

There are many dental implant overdenture attachment systems available today. Some of these overdenture attachments connect to a bar that is fabricated between two or more implants or others simply act as individual studs. The bar design allows for multiple implants to be splinted to distribute occlusal forces and correct for off angled and misaligned implants. These bars can be milled, casted, or sintered and have male portion of the retention system incorporated in the bar itself and the female portion as a clip in the denture, such as hader bars do. Other bar designs may drill and tap, laser weld or cast to a stud attachment such as a LOCATOR to a bar. One of the major downfalls of the bar type overdenture is the requirement for restorative space.

The single implant stud attachments come in a variety of shape and forms. These forms can be resilient and provide some vertical and rotational movement of the denture base or nonresilient (Trushkowsky, 1999). The simplest of the resilient attachments is a sphere. An example of a nonresilient type of attachment most commonly is in the form of a telescopic system with the abutment having a 4-6 degree taper such as the Syncone system (Dentsply Implants, Mölndal, Sweden). Other types of stud systems that have been used are magnetic systems. 
There are numerous studies comparing the retention of different implant attachment systems. These studies not only compare different attachment systems, but also how angulation affects the retention of the different systems. Many of the more recent studies use the LOCATOR (ZEST Anchors LLC, Escondido, CA USA) attachment system as a control. The LOCATOR was introduced in 2001 and gained popularity among practitioners because of its simplicity and minimal vertical restorative space needed. In 2013, Implant Direct introduced a LOCATOR like attachment called the GPS attachment system. Even though these systems look similar Implants Direct has claims of better performance on implants with $10^{\circ}$ of divergence with the GPS attachment system,

\section{Studies of Retention}

There are multiple studies that have tested the retention of different implant attachment systems. A machine that can apply a dislodgement force, such as the Instron universal testing machine, must measure the retention needed for dislodgement of the test system. These machines require a crosshead speed to be inputted for the given test. Previous studies have used a crosshead speed of 50-60 $\mathrm{mm} / \mathrm{sec}$ (Nguyen, Masri, Driscoll, \& Romberg, 2010; Ortegón, Thompson, Agar, Taylor, \& Perdikis, 2009; Williams, Ochiai, Hojo, Nishimura, \& Caputo, 2001).

The studies that compare the effects that implant inclination to the retention values of different attachment systems have produced various results. Yang's study compared the influence of implant inclination on retentive and lateral forces. The study tested locators, ball and magnetic type attachments and concluded that the retentive force decreases with an increase in implant inclination, whereas the lateral force increases, except for in magnetic attachments (Yang, Maeda, Gonda, \& Kotecha, 2011). Ortegón et al used a spherical type of attachment and also found that parallel attachments had the highest median retention value overall when compared to attachments with up to 30 degrees of divergence (Ortegón et al., 2009). It has also been shown that implant angulations negatively affect attachment retention longevity (Al-Ghafli, Michalakis, Hirayama, \& Kang, 2009). Stephens et al studied retention values of LOCATORS during cyclic seating and unseating at 0,10 and 20 degrees of divergence (Stephens et al., 2014). At the start of the experiment the $10^{\circ}$ and $20^{\circ}$ group showed an increase in retention of $38 \%$ and $13 \%$ respectively. After 5500 cycles, there was no significant difference in retention between any of the groups 


\section{Chapter III}

\section{Materials and Methods}

\section{Construction of the Apparatus}

A square acrylic rod (Plastic-Craft Products, West Nyak, NY USA) was cut into blocks measuring 1 inch $x 1$ inch $x 1.5$ inches (Figure 1-A). Four sample groups were made consisting of five samples in each group. Each sample will have a lower block consisting of 2 analogs and an upper block consisting of the housings and an eyebolt for attachment to the testing machine. The first two sample groups will be constructed with two parallel LOCATOR analogs and two parallel GPS analogs. The next two sample groups will be two LOCATOR analogs with 10 degrees of divergence and two GPS analogs with 10 degrees of divergence.

A wooden jig was constructed so that it could be stabilized to the table of a drill press and allow for the acrylic blocks to be repositioned for consecutive drilling in the same spot (Figure 1-B). The first block was marked to reference the position of the proposed analogs so they would be $12 \mathrm{~mm}$ apart. The jig was attached to the drill press table set at 0 degrees and the first block was drilled at the first reference point to a width slightly larger than a LOCATOR analog and a depth that allow the analog head to be $2-3 \mathrm{~mm}$ above the acrylic (Figure 1-C). The depth gauge was locked and four more blocks were drilled for a total of five blocks. Next, the drill bit was changed and depth was adjusted to allow for the GPS analog to fit so that 2-3 $\mathrm{mm}$ was above the acrylic. Five blocks were drilled for the GPS analog. The Jig was adjusted to allow for the drill to line up to the second reference point on the first block and stabilized. The drill was changed for the one that corresponded to the locator and the depth adjusted. The previous five LOCATOR blocks were drilled producing the holes for the parallel LOCATOR group. This was repeated for the previously drilled GPS analog group producing the parallel GPS group.

The above procedure was repeated, but the table of the drill press was angled and locked at 5 degrees from the midline of the block to allow for the two holes to be drilled at a total of 10 degrees of divergence between the two (Figure $1-D$ ). Five LOCATOR analog blocks were drilled for the angled LOCATOR group and five GPS analog blocks were drilled for the angled GPS group.

The drill press table was set at 0 degrees and the middle of a new block was marked so the hole for the eyebolt of the top block could made. The jig was repositioned and stabilized so the drill lined up with the mark and depth gauge was locked. Twenty new blocks that were used for the top block were drilled to allow for the attachment of an eyebolt. The abutment analogs were secured into their respective blocks with integrity (Dentsply Caulk, Milford, DE USA) (Figure 1 - E). Relief was burred into the top blocks to allow for space to pick up the housings of the LOCATOR or GPS 
systems. The block out o rings and attachment housings were placed on the abutment analogs on their respective blocks. Teflon tape was then placed over the exposed acrylic of the block around the abutment and housings to act as a separating medium. Clear orthodontic resin (Dentsply GAC, Islandia, NY USA) was mixed and placed in the relief area of the upper blocks and then the upper blocks were placed on the lower blocks so the resin would be allowed to polymerize around the attachment housings (Figure $1-\mathrm{F}$ ). An alignment jig was used to position the upper and lower blocks to allow the flat edges of the blocks to align. Once the resin was fully polymerized, the upper and lower blocks of each sample were marked and separated. An eyebolt was then screwed into the top of the top block (Figure $1-\mathrm{G}$ and $\mathrm{H}$ ). The black processing inserts for both attachment systems was replaced with a blue $1.5 \mathrm{lb}$. retentive inserts for all the housings.

A Sil-tec (Ivoclar Vivadent Inc., Amherst, NY USA) putty index was made on the Instron vice so that each block could be repositioned and tightened in the same position for each test. A metal chain was fixed to the load cell of the Instron machine. The bottom of the chain was attached to the eyebolt of the top block of each sample when it was tested (Figure 2).

\section{Research Design}

There were five blocks made for each of the four combinations (Figure 3) that were tested by using a retentive $1.5 \mathrm{lb}$. matrix in its corresponding housing:

1. 2 parallel LOCATOR attachments

2. 2 LOCATOR attachments at 10 degrees to total divergence

3. 2 parallel GPS attachments

4. 2 GPS attachments at 10 degrees of total divergence

\section{Protocol}

The study was designed to use an Instron 5565 mechanical testing machine (Instron, Northwood, MA USA), which is commonly used to test the mechanical properties of materials. The blocks were separated and put together by hand except for the recorded pulls. The Instron Machine was connected to the sample block for pulls $1,50,100,150,200,250,300,350,400,450$ and 500. The blocks were separated at $50 \mathrm{~mm} / \mathrm{min}$. The force to dislodge the blocks was recorded

\section{Statistical Analysis}

The statistical analysis was accomplished by an ANOVA using JMP software (SAS, Cary, NC USA). 



E
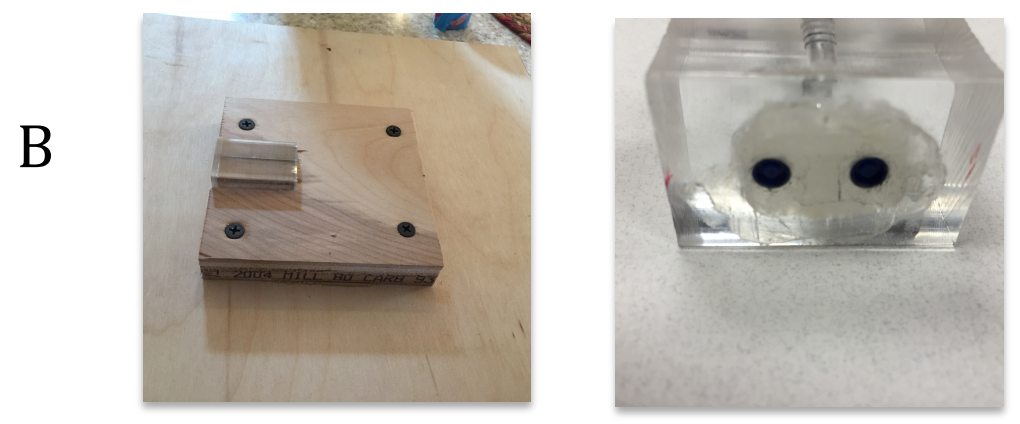

F

C
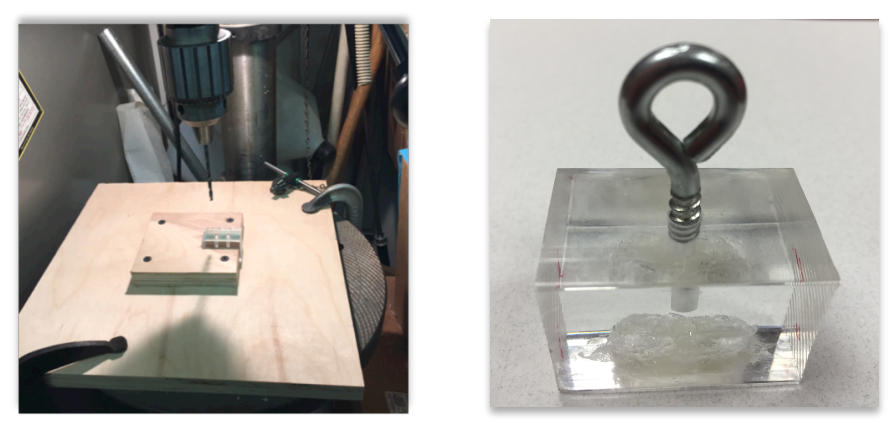

G

D
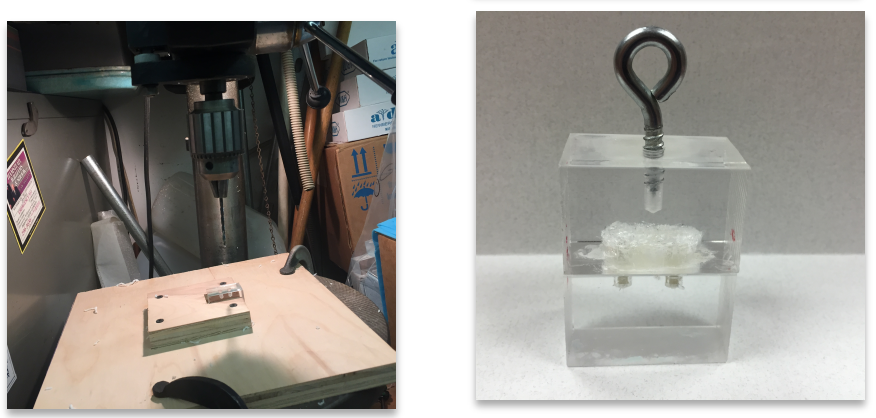

H

A - Acrylic rod cut into blocks, B - Wooden positioning jig, C Parallel holes drilled, D - Holes with 10 degrees of divergence drilled, E - Analogs placed in block, F - Housings picked up with black processing cap, G - Eyebolt placed, H - Finished sample 
Figure 2 - Instron Testing Machine

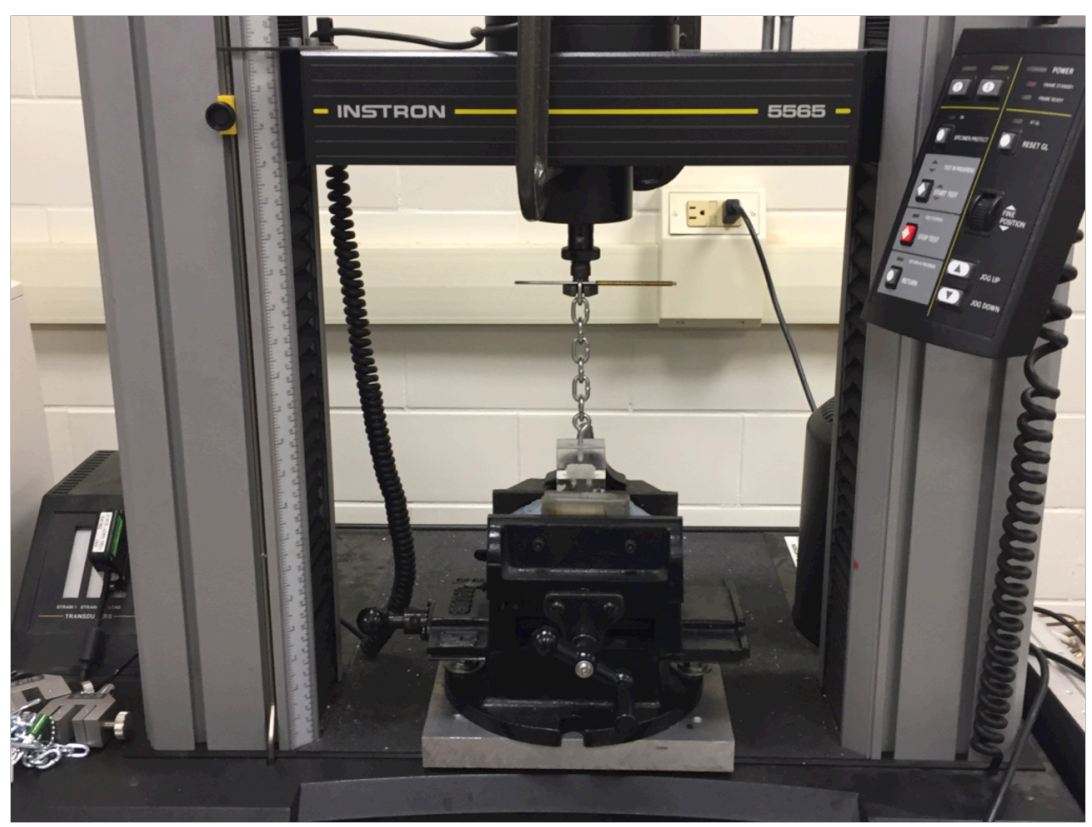

Figure 3 - Configuration of Testing Groups

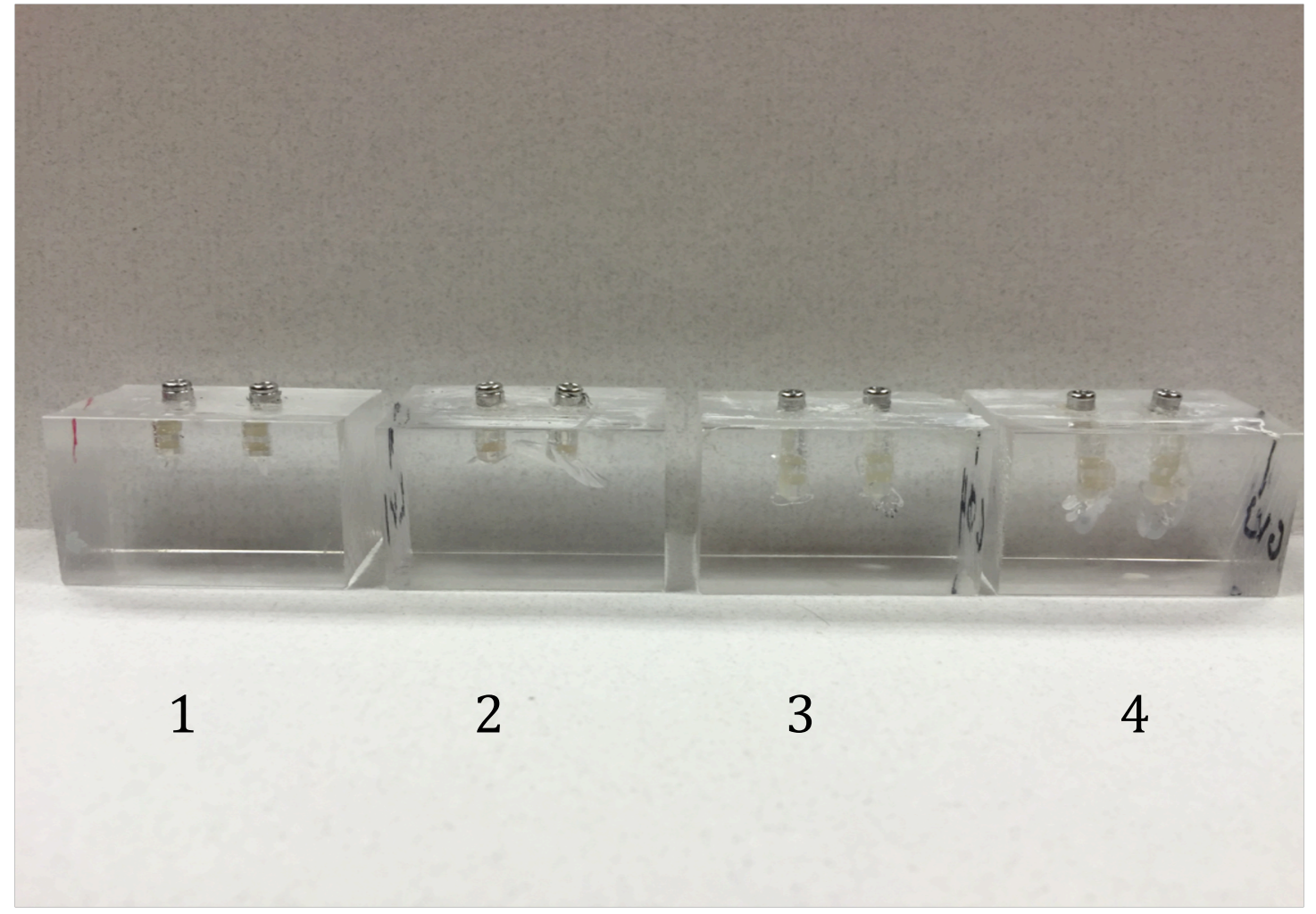

1- parallel LOCATORs, 2 - LOCATORs with 10 degrees divergence, 3 - parallel GPS, 4 - GPS with 10 degrees of divergence 


\title{
Chapter IV
}

\author{
Results
}

The retentive forces were recorded for each sample in the 4 combinations at pulls 1 , $50,100,150,200,250,300,350,400,450$ and 500 . The mean force for dislodgement and standard deviation was computed for each pull of every sample group and then plotted individually in figure 4-7 and the as a group in figure 8

\section{Figure 4 - Means and Standard Deviation plot for parallel GPS} attachment

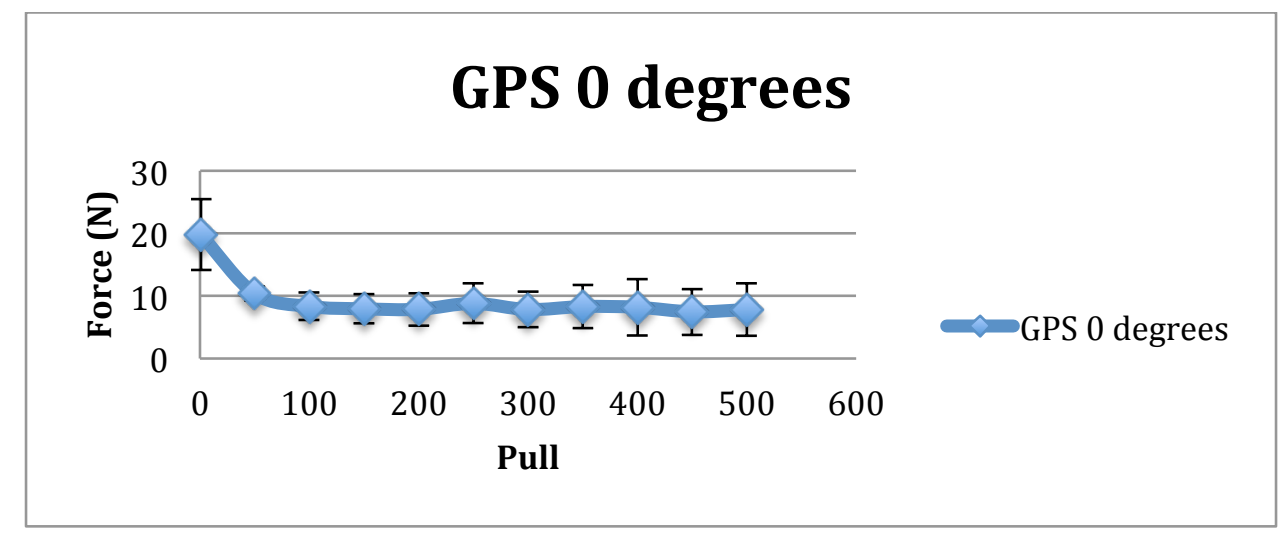

Figure 5 - Means and Standard Deviation plot for parallel LOCATOR attachments






\section{Figure 6 - Means and Standard Deviation plot for Locator attachments with 10 degrees of divergence}

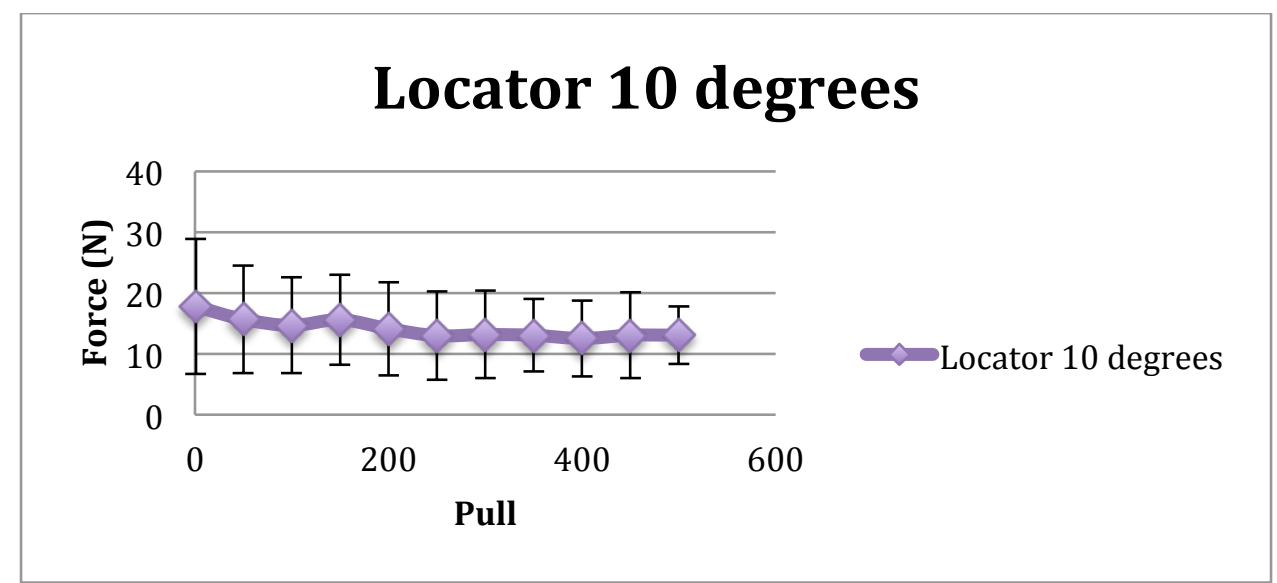

Figure 7 - Means and Standard Deviation plot for GPS attachments with 10 degrees of divergence

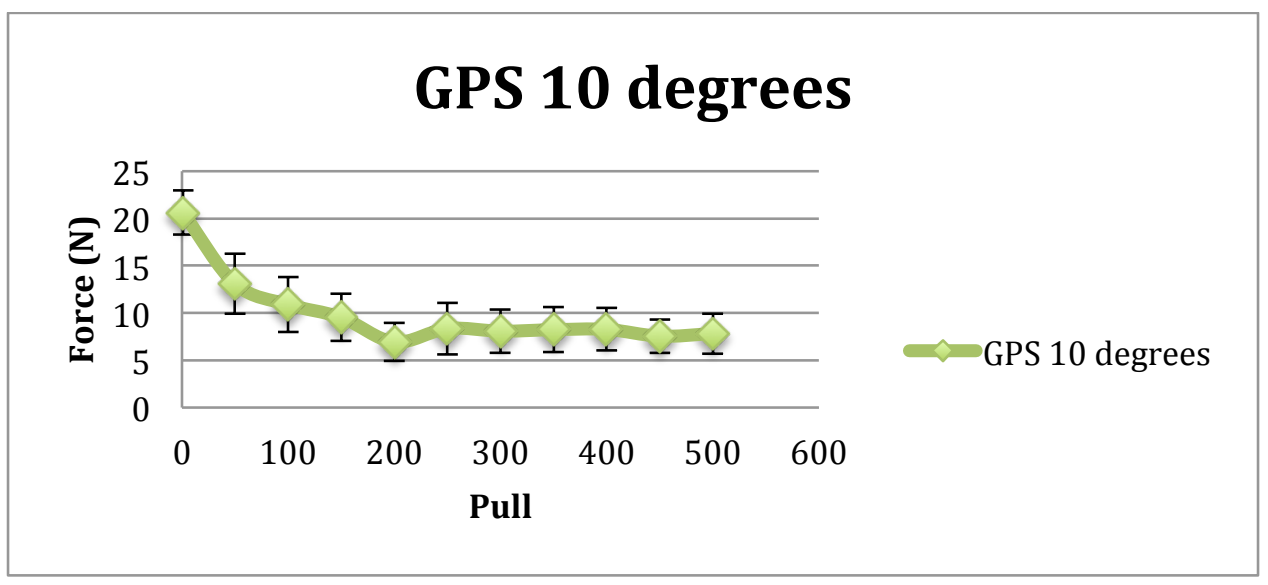

An analysis of variance compared all the groups as a whole. When a test with random effects compared the interactions of the data the three interactions that were significant were attachment, pull, and attachment with pull as shown in Table 1. The least squares means was calculated by attachment (Table-2) and was calculated and plot for the interaction of angle and attachment seen in Table -3 and Figure -9 . The least squares means plot for the pull and interaction of the pull and 
attachment can be seen in Figures 10 and 11 respectively. Table -4 shows the comparison of the means for pull 1 and pull 500 for each sample group

\section{Figure 8 - Means plot for Locator and GPS attachments that are parallel or have 10 degrees of divergence}



\section{Table 1 - Tests with Random Effects}

Source

Angle

Attachment

Angle*Attachment

Pull

Angle*Pull

Attachment ${ }^{\star}$ Pull

$\begin{array}{rrrrr}\text { SS } & \text { MS Num } & \text { DF Num } & \text { F Ratio } & \text { Prob > F } \\ 64.64 & 64.64 & 1 & 0.31 & 0.5836 \\ 1920.40 & 1920.40 & 1 & 9.30 & 0.0076^{*} \\ 157.37 & 157.37 & 1 & 0.76 & 0.3956 \\ 1036.59 & 103.66 & 10 & 21.11 & <.0001^{*} \\ 70.65 & 7.07 & 10 & 1.44 & 0.1671 \\ 438.79 & 43.88 & 10 & 8.93 & <.0001^{*}\end{array}$

The p-value for the type of attachment was .0076 making the attachment a significant variable. The p-value for the angle was .05836 and the p-value for interaction of the angle and type of attachment was .3956 making both of these not significant. When comparing the data as a whole by attachment type, the mean force needed to dislodge the GPS attachment was 9.64 $\mathrm{N}$ and the Locator attachment was 15.44 $\mathrm{N}$ as shown in table 2. The p-value for the interaction of the attachment type 
and angle was 0.3956 showing that it was not significant. The least squares means for attachment and angle can be seen in Table 3 and plotted in Figure 9.

\section{Table 2 - Least Squares Means Table by Attachment}

$\begin{array}{lrcc}\text { Level } & \begin{array}{r}\text { Least Sq } \\ \text { Mean }\end{array} & \text { Std Error } & \text { Mean } \\ & 9.64 & 1.37 & \\ \text { GPS } & 15.55 & 1.37 & 15.64 \\ \text { Locator } & & \end{array}$

Table 3 - Least Squares Means Table by angle and attachment

$\begin{array}{lrr}\text { Level } & \begin{array}{r}\text { Least Sq } \\ \text { Mean }\end{array} & \text { Std Error } \\ & 9.34 & \\ \text { 0,GPS } & 16.94 & 1.94 \\ \text { 0,Locator } & 9.94 & 1.94 \\ \text { 10,GPS } & 14.16 & 1.94 \\ \text { 10,Locator } & & 1.94\end{array}$

Figure 9 - Least Squares means by angle and attachment

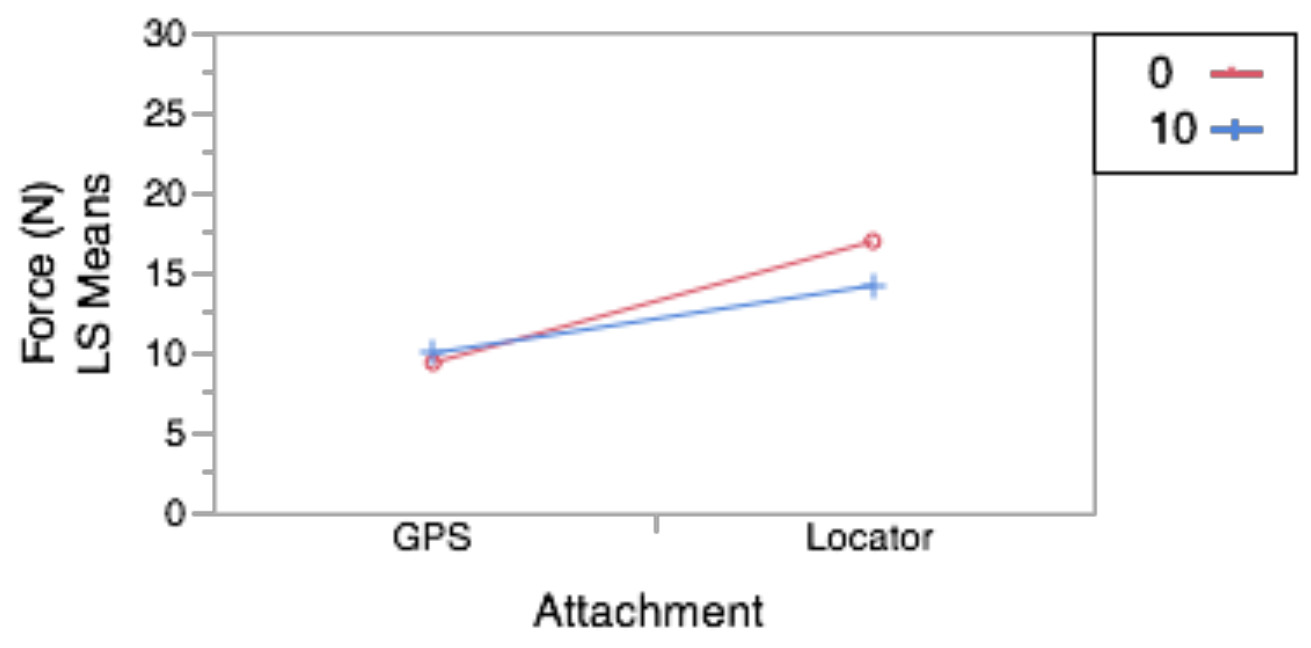


The p-value was $<.0001$ for pull and for the interaction of pull and attachment showing those were significant variables significance. The least squares means plot for pull and the interaction pull and attachment can be shown in Figure 10 and 11.

Figure 10 - Least Square Means Plot for Pull

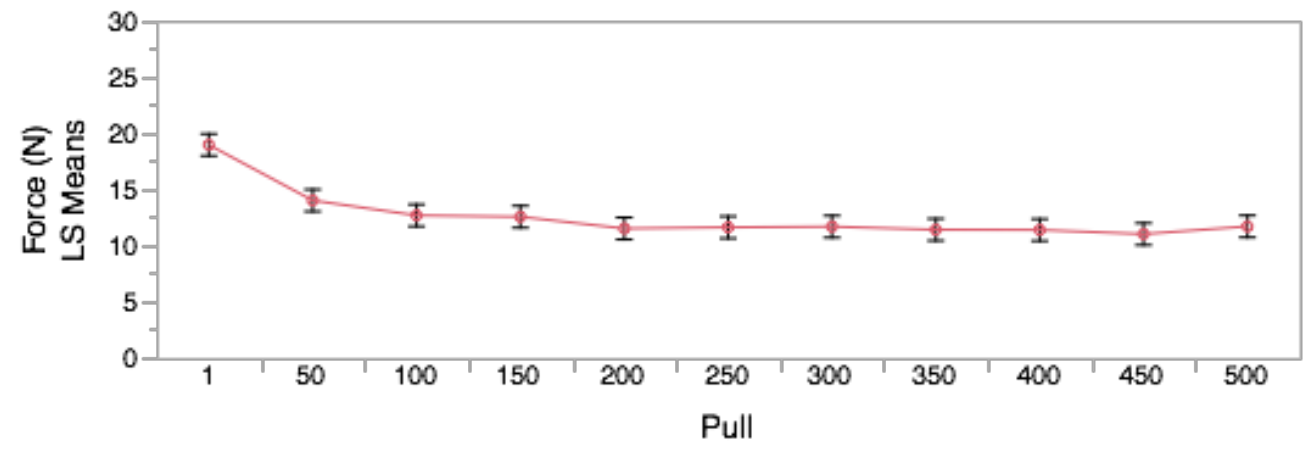

Figure 11 - Least Square Means Plot for Pull and Attachment

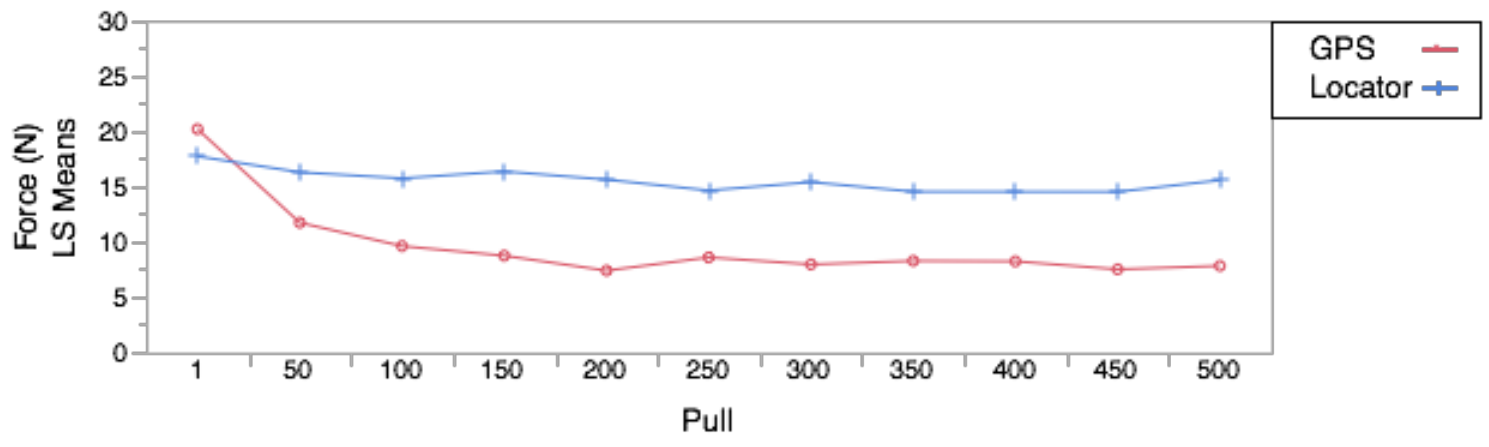




\section{Table 4 - Initial and Final Retention for the Sample Groups}

\begin{tabular}{|l|c|c|c|c|}
\hline \multicolumn{4}{|c|}{ Comparison of Pull 1 to Pull 500 for each sample group } \\
\hline Pull 1 (N) & Pull $500(\mathrm{~N})$ & $\begin{array}{c}\text { Lost } \\
\text { retention (N) }\end{array}$ & $\begin{array}{c}\% \text { lost } \\
\text { retention }\end{array}$ \\
\hline LOCATOR parallel & 17.72 & 18.07 & +0.31 & +1.75 \\
\hline LOCATOR 10 & 17.76 & 13.08 & 4.68 & 26.35 \\
\hline GPS parallel & 19.79 & 7.82 & 11.97 & 60.49 \\
\hline GPS 10 & 20.62 & 7.82 & 12.80 & 62.08 \\
\hline
\end{tabular}

\section{Discussion}

This study investigated the dislodging forces necessary to separate acrylic blocks modeling a mandibular overdenture attached to two implants by the Locator or GPS dental implant attachment system. To better simulate deviations from ideal the implants were either positioned ideally in parallel or had a divergence of 10 degrees between them. Since the interaction of the attachment angle was statistically significant, the null hypothesis must be rejected since there was a significant difference in the retention of the LOCATOR and GPS attachment systems on parallel or divergent implants. The LOCATOR had a mean force of dislodgement of $15.54 \mathrm{~N}$, when compared to the $9.64 \mathrm{~N}$ of the GPS this is an increase of $5.91 \mathrm{~N}$ or $61 \%$. This would suggest that clinically the LOCATOR would be significantly more retention on all cases were the implants had $10^{\circ}$ of divergence or less. There does not seem to be a difference within each system with respect of how they perform on parallel or angled implants, as depicted in Table 3 and Figure 9.

The LOCATOR had a decrease in initial retention of $2.78 \mathrm{~N}$ or $16 \%$ and the GPS had an increase of $.61 \mathrm{~N}$ or $6.5 \%$ on the angled implants when compared to the parallel implants. Neither one of these observations were significant either statically or clinically. This would suggest that both systems accommodate angled implants to a similar degree.

There were two interactions involving the pull that were statistically significant in Table -1 . The first was the pull by itself as seen in the Figure -10 . This shows that regardless of the attachment the majority of retention loss occurred in the first 50100 pulls. The second significant interaction is pull and attachment, which gives a more detailed look at this notion as seen in Table - 11. This plot shows that the GPS system loses a significant amount of its initial retention while the LOCATOR stays at a fairly consistent level. It can also be seen that even though the GPS has higher initial retention it quickly falls below the retention provided by the LOCATOR after 
about 50 pulls. Clinically the LOCATOR provides the clinician with an attachment that retains most of its initial retention over 500 cycles of seating and unseating.

The comparisons of the means of pull 1 and pull 500 for each sample group can be seen in Table -4 . Over $60 \%$ of the initial retention of the GPS system was lost by pull 500 regardless of the angulation of the implants. The LOCATOR on angled implants lost about $26 \%$ of its initial retention. The LOCATOR on parallel implants actually gained almost $2 \%$ of retention over the course of the test. This gain is not statistically significant. Clinically an attachment that maintains its retention for an extended period of time could lead to less overdenture maintenance and possible greater patient satisfaction. This study also demonstrated that implants placed in parallel demonstrate better performance and advocate the use of a surgical guide with angulation control to improve placement.

Stephens et al (Stephens et al., 2014) study compared the retention of blue Locator inserts on Locator analogs with up to 5500 seating and unseating cycles. Stephens's data for the first 500 cycles was plotted with the data from this experiment in Figure 12. After 500 cycles the parallel and $20^{\circ}$ samples had about the same retentive capacity of $18 \mathrm{~N}$. There was a difference of about $6 \mathrm{~N}$ in the $10^{\circ}$ samples, which could be from the difference in the tolerance of manufacturing of the LOCATOR analogs but the overall trends were similar.

\section{Figure 12 Stephens' and Wine's retentive capacity of LOCATOR attachments}

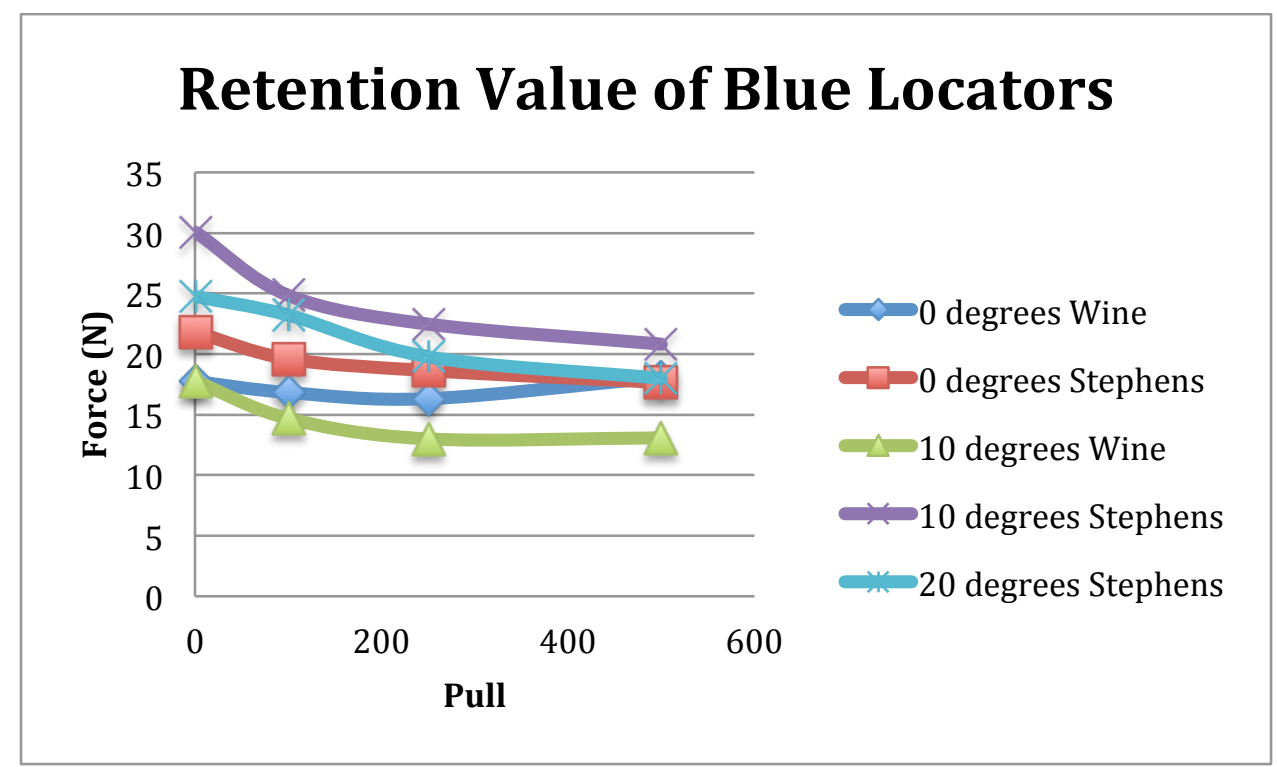


The 500 cycles in this study would correlate to around 4 months of seating and unseating of the overdenture by the wearer (Al-Ghafli et al., 2009). There are many overdenture patients whose recall appoints are in excess of 4 months. In future studies it may be clinically relevant to continue the cycles to 6 months (720 pulls) or 12 months (1,440 pulls) of simulated seating and unseating. Future studies may also which to investigate the functioning of the attachments in the aqueous environment to better simulate the oral environment. Figure 10 shows that after 100 pulls or about 1 month of simulated seating and unseating there is very little retention lost in either system up to the 500 pulls. This could suggest that there may be a clinical benefit to bringing new overdenture wearers back 1-month post insertion to check the wearers satisfaction with the retention.

\section{Chapter V}

\section{Summary}

The study attempted to compare the retentive capacity of the LOCATOR and GPS dental implant anchor systems on two parallel implants or two implants with 10 degrees of divergence. The data suggests the GPS system may provide more retention on the first pull, but as the overdenture is seated and unseated by the patient, the LOCATOR will provide greater retention. The LOCATOR system may provide the practitioner and denture wearer with a attachment that maintains more of its retentive capacity after 500 cycles of seating and unseating on implants that are parallel or have 10 degrees of divergence between them.

\section{Conclusions}

1. The GPS system has more initial retention but the LOCATOR retains its retention much better over 500 cycles of seating and unseating.

2. The LOCATOR preformed better on two implants that were parallel or had 10 degrees of divergence between them than the GPS system. 


\section{References}

Ahuja, S., \& Cagna, D. R. (2010). Defining available restorative space for implant overdentures. The Journal of Prosthetic Dentistry, 104(2), 133-136. doi:10.1016/S0022-3913(10)60107-2

Al-Ghafli, S. A., Michalakis, K. X., Hirayama, H., \& Kang, K. (2009). The in vitro effect of different implant angulations and cyclic dislodgement on the retentive properties of an overdenture attachment system. The Journal of Prosthetic Dentistry, 102(3), 140-147. doi:http://dx.doi.org/10.1016/S00223913(09)60134-7

Burns, D. R. (2000). Mandibular implant overdenture treatment: Consensus and controversy. Journal of Prosthodontics, 9(1), 37-46. doi:10.1111/j.1532849X.2000.00037.x

Burns, D. R., Unger, J. W., Coffey, J. P., Waldrop, T. C., \& Elswick, R. K. (2011). Randomized, prospective, clinical evaluation of prosthodontic modalities for mandibular implant overdenture treatment. The Journal of Prosthetic Dentistry, 106(1), 12-22. doi:10.1016/S0022-3913(11)60088-7

Dias, R., Moghadam, M., Kuyinu, E., \& Jahangiri, L. (2013). Patient satisfaction survey of mandibular two-implant-retained overdentures in a predoctoral program. The Journal of Prosthetic Dentistry, 110(2), 76-81. doi:10.1016/S00223913(13)60343-1 
Ettinger, R. L. (2014). Do root supported overdentures have a good prognosis in general dental practice?. Oral Health,

Feine, J. S., Carlsson, G. E., Awad, M. A., Chehade, A., Duncan, W. J., Gizani, S., ... Wismeijer, D. (2002). The McGill consensus statement on overdentures. mandibular two-implant overdentures as first choice standard of care for edentulous patients. Gerodontology, 19(1), 3-4. doi:10.1111/j.17412358.2002.00003.x

Fenton, A. H. (1998). The decade of overdentures: 1970-1980. The Journal of Prosthetic Dentistry, 79(1), 31-36. doi:10.1016/S0022-3913(98)70190-8

Fueki, K., Kimoto, K., Ogawa, T., \& Garrett, N. R. (2007). Effect of implant-supported or retained dentures on masticatory performance: A systematic review. The Journal of Prosthetic Dentistry, 98(6), 470-477. doi:10.1016/S00223913(07)60147-4

Lee, C. K., \& Agar, J. R. (2006). Surgical and prosthetic planning for a two-implantretained mandibular overdenture: A clinical report. The Journal of Prosthetic Dentistry, 95(2), 102-105. doi:10.1016/j.prosdent.2005.11.017

Lee, J., Kim, H., Shin, S., \& Bryant, S. R. (2012). Number of implants for mandibular implant overdentures: A systematic review. The Journal of Advanced Prosthodontics, 4(4), 204. doi:10.4047/jap.2012.4.4.204 
Misch, C. E. (2005). Maitenance of dental implants. Dental implant prosthetics (pp. 587). St. Louis, Mo: Elsevier Mosby.

Nguyen, C. T., Masri, R., Driscoll, C. F., \& Romberg, E. (2010). The effect of denture cleansing solutions on the retention of pink locator attachments: An in vitro study. Journal of Prosthodontics, 19(3), 226-230. doi:10.1111/j.1532849X.2009.00550.x

Ortegón, S. M., Thompson, G. A., Agar, J. R., Taylor, T. D., \& Perdikis, D. (2009). Retention forces of spherical attachments as a function of implant and matrix angulation in mandibular overdentures: An in vitro study. The Journal of Prosthetic Dentistry, 101(4), 231-238. doi:http://dx.doi.org/10.1016/S00223913(09)60045-7

Rahn, A. O., \& Heartwell, C. M. (1993). Complete denture impressions. Textbook of complete dentures (pp. 227)

Sadowsky, S. J. (2001). Mandibular implant-retained overdentures: A literature review. The Journal of Prosthetic Dentistry, 86(5), 468-473. doi:10.1067/mpr.2001.119921

Stephens, G. J., di Vitale, N., O'Sullivan, E., \& McDonald, A. (2014). The influence of interimplant divergence on the retention characteristics of locator attachments, a laboratory study. Journal of Prosthodontics, 23(6), 467-475. doi:10.1111/jopr.12144 
Swenson, M. G., 1892. (1959). Complete dentures. (pp. 23). United States:

Tallgren, A. (2003). The continuing reduction of the residual alveolar ridges in complete denture wearers: A mixed-longitudinal study covering 25 years. The Journal of Prosthetic Dentistry, 89(5), 427-435. doi:10.1016/S00223913(03)00158-6

Thomason, J. M., Lund, J. P., Chehade, A., \& Feine, J. S. (2004). Patient satisfaction with mandibular implant overdentures and conventional dentures 6 months after delivery. The Journal of Prosthetic Dentistry, 91(2), 197-197. doi:10.1016/j.prosdent.2003.12.011

Trushkowsky, R. (1999). Facilitating the trasition to a full denture with ERA attachments. Dialogues in Esthetic Dentistry, 1(1)

Van Waas, M., Jonkman, R., Kalk, W., Van 't Hof, M., Plooji, J., \& Van Os, J. (1993). Differences two years after tooth extraction in mandibular bone reduction in patients treated with immediate overdentures or with immediate complete dentures.. Journal of Dental Research, 72(6), 1001.

Williams, B. H., Ochiai, K. T., Hojo, S., Nishimura, R., \& Caputo, A. A. (2001). Retention of maxillary implant overdenture bars of different designs. The Journal of Prosthetic Dentistry, 86(6), 603-607. doi:10.1067/mpr.2001.120838

Wismeijer, D., Waas, M. A. J. V., Vermeeren, J. I. J. F., Muldel, J., \& Kalk, W. (1997). Patient satisfaction with implant-supported mandibular overdentures. 
International Journal of Oral \& Maxillofacial Surgery, 26(4), 263-267.

doi:10.1016/S0901-5027(97)80864-8

Wright, C. R. (2004). Evaluation of the factors necessary to develop stability in mandibular dentures. The Journal of Prosthetic Dentistry, 92(6), 509-518. doi:10.1016/j.prosdent.2004.08.002

Yang, T., Maeda, Y., Gonda, T., \& Kotecha, S. (2011). Attachment systems for implant overdenture: Influence of implant inclination on retentive and lateral forces. Clinical Oral Implants Research, 22(11), 1315-1319. doi:10.1111/j.16000501.2010.02137.x

Zarb, G. A., Bolender, C. L., Hickey, J. C., \& Carlsson, G. E. (1990). Biomechanics of the edentulous state. Boucher's prosthodontic treatment for edentulous patients (10th ed., pp. 3)

Zarb, G. A., Bolender, C. L., Eckert, S. E., \& Boucher, C. O. (2004). Prosthodontic treatment for edentulous patients: Complete dentures and implant-supported prostheses. St. Louis: Mosby. 


\section{Curriculum Vitae}

Name: Christopher Heath Wine

Date of Birth: 08-10-1981

Place of Birth: Wheeling, WV

Education:

August 2000 - 2003

West Liberty University

West Liberty, WV

August 2003 - 2007

West Virginia University

School of Dentistry

Morgantown, WV 26505

Doctorate of Dental Surgery

July 2012 - present

West Virginia University

School of Dentistry

Department of Graduate Prosthodontics

Masters of Science - Prosthodontics 